\title{
Implications of Adolescents' Perceptions and Values for Planning and Design
}

Camille Passon, Project Design Consultants, San Diego, CA

Daniel Levi, California Polytechnic State University, San Luis Obispo, CA

Vicente del Rio, California Polytechnic State University, San Luis Obispo, CA

\begin{abstract}
Adults are responsible for selecting and creating the environments where their children and youth live, but it is not clear if these places contain the qualities that young people value. In this study, high school students from three communities were surveyed regarding their perceptions of where they live to determine whether indicators identified by previous research as qualities that youth value are present in those communities and perceived to be important. Although the results suggest the indicators are important to the adolescents, their communities lack a majority of them and this has contributed to low satisfaction ratings. Recommendations for better integrating adolescents into public participation processes are discussed along with implications for planning and design.
\end{abstract}

Keywords: community participation; youth's perceptions; urban design; environmental values 
Planners and designers have always been concerned about improving the quality of life for the residents in a community. Discovering how people use, perceive, and value their environments is a major step in this quest, and public participation is the common means through which community needs are identified and incorporated into plans. One significant segment of the population that is frequently overlooked in this process is youth or adolescents - people in their teens or early twenties. There is some research regarding how children evaluate their environments, which has resulted in a greater understanding of how to make a community a good place to grow up. However, youth are rarely considered and their needs are not heard. They are often excluded from opportunities to participate in the process of planning their own communities, which evolve without responding to the unique needs of these young residents (Frank 2006).

Young people have little to no power when deciding where they are going to live. Adults are ultimately responsible for selecting and creating the environments where children and youth live. Research on housing choice and residential satisfaction shows that adults prefer small, safe, suburban settings to raise children (Vliet 1981). But do the youth themselves perceive these as desirable places to live? There is very little research examining this question and it is not clear whether youth share the same values as children, or whether their needs change over time. This article discusses a study that examined how adolescents evaluate and value their communities, and the planning and design implications of such perceptions. High school seniors (17 to 18 years of age) were studied in three communities in San Luis Obispo County, CA: Cambria, Paso Robles, and San Luis Obispo. They were surveyed regarding their perceptions of community quality indicators that have been identified as determinants of whether an urban area is a good place for children to grow up. The study expands on the quality indicators originally identified in Growing Up in Cities — an international project by UNESCO — and includes social integration, variety of interesting settings, safety and freedom of movement, peer meeting places, cohesive community identity, and green areas (Lynch 1977; Chawla 2002). 


\section{Participation and Place Dependency}

The community participation movement emerged in the 1960s based on the fundamental belief that, in democratic societies, "the individual has the right to be informed and consulted and to express his views on matters which affect him personally" (Sewell and Coppock 1977, 1). The concept of community participation is based on the principle that the environment works best if the people affected by its changes are actively involved in its creation and management instead of being treated as passive consumers (Sanoff 2000). When community members participate in the decision-making process, their involvement often results in places that enrich people's lives by responding to their needs and aspirations as well as giving people a sense of pride and investment in their communities.

Who participates in planning and design processes varies, depending on a number of different factors (Sanoff 2000). People are more likely to participate if they have an economic, social, or political interest in the outcome of a particular decision. The degree of involvement depends on individual skills, roles in the community, and the willingness to commit time and energy. Also, older, higher educated, and more affluent individuals usually are more aware of the issues involved and have more motivation, skills, and resources - characteristics that make them more likely to participate than others.

One disadvantaged group that often does not have the opportunity to participate is young people. Actually, it is not unusual to see them referred to as a subgroup of the "special populations" category, together with the "mentally ill" and the "elderly and handicapped," in existing literature (Bechtel 1997, 168). Before the age of eighteen, children and youth are dependent on their parents and other adults, and "the definition of children's environments remains that part of the environment largely made by adults for children" (Bechtel 1997, 458). Comprehensive plans often have few references to youth, except when planning for schools or other youth facilities (Frank 2006). Plans do not reflect the many ways youth interact with communities. The young have little or no say in where they are going to live, nor do they have any voice in how their communities develop. They have no power to vote on decisions that have 
huge impacts on their lives, nor are they fully aware of how these decisions are made. Nevertheless, they are going to be users of these environments and their social behaviors and individual values are influenced by them.

A child and youth's development depends largely on their relationships and exchanges with the world around them (Piaget 1967, Donnelly 1980). By allowing social encounters, the environment plays a fundamental role in the formation of a child's personality and his or her capacity to deal with others. "A sense of environmental competence ... may be the precursor of the child's social competence" (Donnelly 1980, 63). This is especially true for teenagers who depend largely on socializing in outdoor spaces or in spaces that are left over by adults; places where they can "hang out," such as streets, public plazas, shopping malls, and so on (Lynch 1977; Bechtel 1997). Communication and contact with other people is very important to adolescents (Bechtel 1997). Teens want places where they can be with their friends and meet new people (Owens 1988; Hester et al 1988).

Because social encounters normally happen in a space outside the home, the sociocultural meanings of public spaces are fundamental for teenagers, and thus, place-dependency. Rapoport $(1977,1982)$ and Tuan $(1974,1977)$, for instance, stress the importance of shared sociocultural meanings in the construction of place and in place identity. Stokols and Shumaker (1981) propose a place-dependence construct emphasizing the shared components of the bond between people and places and, thus, between individuals pertaining to the same group. Meaningful places to a group are where the group knows how to behave and what to expect from the place, but also where the group shares symbolic and affective associations with the place. Single places are situated in a "place system" or a complex set of placesfrom home, to city, to nation - that have interdependent sociocultural meanings (Rapoport 1977). The city and its network of public spaces become an important scenario where teenagers develop their personalities and social roles. This is why participation of teenagers in the planning and design of the built environment and of their own places is so important, and why teenagers as a social group should participate in making decisions that affect their communities. 
However, this does not happen. Research has shown a declining interest and involvement in civic affairs, especially among young people (Miller and Piscatelli 2004). Because of curriculum changes, today's high school students do not receive a comprehensive citizenship education, one that is aimed at instilling the knowledge, skills, and dispositions necessary for effective civic participation (Miller and Piscatelli 2004). The knowledge that students receive in school regarding American government is usually not relevant to their everyday lives. They cannot relate to it nor do they understand how they can become active citizens before they reach the voting age.

\section{Attitudes Toward Children and Youth}

The current views of children and youth may help to explain why adults are hesitant to allow young people to participate in planning and urban design. Children and youth are often discriminated against simply because of their age. Stoneman (1988) points out that young people, because they lack life experience, are believed to be inferior to adults, who often believe that children lack the maturity and capability to participate fully in matters that affect them. This paternalistic view of the child can "stifle the child's capacity to interact independently with and shape her or his environment" (Simpson 1997, 908).

Although both children and youth are subject to bias by adults, the perceptions of younger children are often different from those of older children or youth. For instance, while urban planning and design usually centers on the need to protect children from real and perceived harm, when dealing with youth there is a concern to design places that will minimize the harm and destruction that they may cause (Simpson 1997). It is unclear at what point adults worry less about potential threats to the safety and welfare of their children and start worrying more about the threats their children pose to others.

Survey research shows that many Americans have negative views of adolescents — using words such as rude, irresponsible, and wild to describe teenagers - and more than half also describe young children disapprovingly (Duffet, Johnson, and Farkas 1999). Low-income and minority teens are stereotyped as 
welfare mothers, gang members, and drug users who reject mainstream values (Medoff and Sklar 1994). Adults do not think that youngsters today will grow up to make America a better place and they believe that juvenile violent crime and teen pregnancy are on the rise (Whitman 2005). These perceptions stem from a fear known as ephebiphobia, or the "persistent and unwarranted fear of teenagers" (Whitman 2005, 4).

In reality, adolescents today are less likely than their parents were to smoke, do hard drugs, get pregnant, commit violent crimes, drop out of school, and drive drunk (Whitman 2005). They are more likely to perform volunteer work than the preceding generation, and they are more likely to graduate from high school and college. In addition, they are performing as well or slightly better than the previous generation on aptitude and achievement tests (Whitman 2005).

Ephebiphobia engenders a suspicion of youth when they are encountered in public settings. Even when teens are obviously not engaged in inappropriate behavior, they are asked to go somewhere else by adults because it is assumed that they will soon be causing trouble (Owens 2002). Merchants, for example, are opposed to teens gathering in front of their stores because they are afraid they will scare away legitimate customers. Equally, city officials, parents, and other adults interpret their "hanging out" as an unproductive use of time that leads to delinquency. These perceptions lead to the implementation of policies and design practices that discourage the use of public spaces by teens. In addition to these public policies, design practices have evolved that exclude youth from public spaces in a more subtle manner. In shopping malls, for example, seating areas are designed to discourage lengthy stays and, in some instances, bus stops are being relocated to discourage stops at the mall on the way home from school (Owens 2002).

Skateboarding is another activity popular among adolescents that is looked down upon and highly regulated. Communities have been adopting ordinances restricting the use of skateboards in public settings, while providing skate parks so that teens have a specific, legitimate, and acceptable place to 
skate. However, these facilities are restrictive to many skateboarders. Also, the fact that skateboarding may actually be seen as a form of transportation for many adolescents is largely overlooked and not accommodated by skateboard ordinances.

Besides the existing structural barriers and the fact that most institutions involved in planning are adult oriented, societal views of youth do not encourage their participation in planning and decision making in any significant way (Frank 2006). The presence of youth in planning processes is based on the view of youth either as a source of information or a problem to solve, rather than a participating stakeholder group (Checkoway and Gutierrez 2006, Frank 2006). The negative attitudes about adolescents held by adults limit the amount of youth participation, although youth are competent citizens who have a right to participate in changes in their communities. On the other hand, the exclusion of adolescents from public spaces may hinder their development, since socialization and involvement in the daily social life of urban streets helps them to become well-adjusted adults. Consequently, the city needs a culturally rich and meaningful system of public places in which youth are actively involved in planning and designing. Understanding the needs and values of adolescents is a major step toward achieving this goal.

\section{Characteristics of Youth}

Adolescence is the stage of development where a stable adult personality is formed (Erikson 1964). The creation of a unified sense of self is the final developmental stage before adulthood. This identity formation includes the development of a stable sense of self and related beliefs, values, and life plans. The development of the self is tied to developing social relations and connections with one's community.

Compared to early childhood, adolescents shift their focus from their parents to their peers (Cole, Cole, and Lightfoot 2005). They become more mobile and avoid authority. They socialize in larger peer groups of both single and mixed gender. Hanging out becomes an important social activity for these groups. This peer socialization is important for the formation of their personal and social identity and values. Although 
hanging out in public spaces is viewed as a positive recreational activity by youth, adults often perceive this behavior as a problem and a threat to the community (Glendinning et al. 2003).

While younger children often recreate in structured activities that are impacted by facilities such as schools and community recreation centers, adolescents prefer unstructured recreational activities, such as hanging out and socializing with other teens (McMeeking and Purkayastha 1995). This requires tolerant public spaces where they can gather, but restrictions on loitering in public areas limit the adolescents' ability to gather together.

Adolescents have a mixed view of rural communities (Glendinning et al. 2003). They view their family, social networks, and community as supportive and caring, but also feel these features are intrusive and controlling. Rural places are viewed as good places for young children, but not necessarily for adolescents. Young people often view rural communities as safe and are more likely to travel alone, even after dark, but because of limited social activities they feel isolated and bored. Although their life is stable and they have a stronger sense of belonging to the community compared to urban youth, rural youth complain of isolation and deprivation, transportation difficulties, restricted peer group, and limited recreational opportunities.

In the high density, mixed land use of the city, adolescents typically live within walking distances of friends and can hang out at their house (McMeeking and Purkayastha 1995). But in suburban and rural environments, the distances between friends makes access more difficult. Walking by adolescents is related to residential density, land use mix, and access to recreation spaces (Kerr et al. 2007). Living in denser, mixed-use areas and having access to commercial and recreational areas are related to youth walking.

Regardless of location, adolescents complain about the inability to access recreational pursuits (McMeeking and Purkayastha 1995). There is a perceived lack of available recreational spaces and there are social sanctions that prohibit use of these spaces for unstructured activities. Many adolescents view 
having a car as the solution to their access problem. Even when public transportation is available, they often do not use it and complain that the routes and schedule do not meet their needs.

Parents and other adults can take either a constraining or enabling approach toward dealing with conflicts over adolescent social behavior (Cole, Cole, and Lightfoot 2005). If authority figures deal with these conflicts in a too-controlling manner, they limit the development of responsibility, independence, and autonomy in adolescents. On the other hand, allowing adolescents to participate in decisions about their lives helps to encourage healthy psychological and identity development.

By late adolescence, youth are able to think in abstract and political terms about social issues (Adelson 1991). Adolescents have the cognitive abilities of perspective taking, problem solving, and planning, and the knowledge of social norms and values to be able to meaningfully participate in planning and community change programs. Their political thinking and ability to use abstract concepts is similar to adults.

Participation in community activities is good for adolescents. Their personal development is linked to membership and participation in community groups. Youth participation in planning often focuses on ways to improve community livability_-including improved transportation and access to public spaces (Frank 2006). They want to renew public life by providing access to public spaces for interaction. Their participation addresses both youth and community concerns. The information they provide to the planning process and their recommendations are appropriate and feasible. However, adolescents may become cynical and disengaged in the larger social and political processes because of their limited ability to impact them.

\section{Toward the Participation of Youth in Planning}

There are significant barriers to youth participation in planning. Besides the legalistic, economic, and political barriers, most institutions involved in planning are adult oriented and there is little room to 
incorporate youth concerns (Frank 2006). Involving youth in the planning process is also challenging because adults believe that youth are open to manipulation and that they lack the skills and knowledge to meaningfully participate. Youth have limited legal status in the planning process and adults are unsure about how to interact with them.

As pointed out by Driskell (2002), many adults view youth participation in urban planning as an activity with little practical value. In most cases, the presence of youth in planning processes is based on the view of youth either as a source of information or a problem to solve, rather than a participating stakeholder group (Checkoway and Gutierrez 2006, Frank 2006). This stance often leads to ineffective youth participation programs that use children and youth in a token way. In turn, adolescents are sometimes frustrated by the lack of appropriate response from adults about their participation.

One of the difficulties youth have in participating in planning processes seems to be their lack of understanding of the political process and how to encourage the implementation of their ideas. Part of this problem is the power differential between youth and the other participants in the planning process. In many instances, although adults may believe that they are involving youth in planning, they often fail to provide opportunities for young people to participate meaningfully. Involving youth in participatory processes is a means of empowerment, enhancing their role in society, helping their social development, and generating a sense of belonging (Sanoff 2000). "Community development and youth development are inextricably related because both hinge on the basic health of the functions of family and citizenship and are long-term strategies for reducing youth and community problems" (Sanoff 2000, 18).

Youth participation programs should be designed to maximize the opportunity for young people to participate in the decision-making process to the fullest extent of their ability. There should not be a universal notion of what children can or cannot do at certain ages. Rather, opportunities should be provided for a diversity of ways for youth to be involved to maximize their capacity to take an active part 
in their communities. Experience shows that satisfaction comes from the feeling of having influenced the decisions more than from the degree to which a person's needs have been met (Sanoff 2000).

Although it may be hard to initiate and enact programs that use genuine youth participation methods, some communities have developed exemplary models. In Norway, municipal action plans for children and youth are based on national goals stating that young people have to be integrated into society, be given responsibilities, and have opportunities to influence their own living conditions (Moore 1986). In the United States, the Seattle Youth Involvement Network worked in collaboration with the Seattle Planning Department in collecting input from youth for the city's comprehensive plan, and the City of Lemon Grove, California, launched the Lemon Grove Kids City Planning Program to identify the community issues that are most important to local children as part of its General Plan (Mullahey, Susskind, and Checkoway 1999). In Boston, youth were actively involved in Dudley's Young Architects and Planners program, a neighborhood community development effort which involved adolescents in designing a new community center and redesigning a community park (Medoff and Sklar 1994).

In the case of school projects, there are several examples in the United States where participatory methods were used in the design process (Sanoff 1994, 2000). In fact, the National Clearinghouse for Educational Facilities recommends that schools be designed with community participation and that children be part of decision making (Sanoff 2002). Projects that allow children and youth to participate in the construction and operation of their school are positively correlated with greater academic achievement, higher attendance, and better behavior (Rutter 1979; Sanoff 2002). In each of these cases, adults were impressed by the ability of young people to grasp the essence of complex planning issues and their desire to create practical solutions.

There are many benefits to youth participation in planning activities (Checkoway and Gutierrez 2006; Frank 2006). Youth directly benefit from the educational, entertainment, and social aspects of planning; they appreciate having a voice in public affairs and feel more connected to their community. Participation 
helps to develop the knowledge and skills of youth - they learn about their local community, discover how to create community change, and develop planning skills. They also become more confident and assertive, developing enthusiasm for planning and community participation. Communities benefit by having designs that better reflect the needs of all of their citizens.

Youth have the capacity to meaningfully participate in planning activities and they are interested in the planning process (Frank 2006). They have the technical, communication, perspective-taking, and decision-making skills to participate. In a recent review of the literature, Frank (2006) reported that, in most cases, proposals by youth were not implemented because of reasons other than their quality and feasibility. As in most participatory processes, it is important to develop specific approaches for the characteristics of the audience (Checkoway and Gutierrez 2006). Participatory approaches for youth work best when youth and adults work together, and when adults recognize that youth have a valuable contribution to make to the change process.

\section{Children and Youth Perceptions of Urban Quality}

Although research on housing choice and residential satisfaction indicate that adults prefer suburban settings to raise children, children themselves are rarely asked about how they feel living in different types of neighborhoods (Vliet 1981). There are positive and negative aspects to both suburban and city living. Existing research reports that children and youth like quiet, safe, slow, and friendly suburban neighborhoods (Vliet 1981), appreciate having backyards (Homel and Burns 1987), and they list gardens, parks, natural areas, and undeveloped agricultural fields among their favorite places (Owens 1988;

O’Brien 2003; Hester et al. 1988; Lynch 1977; Moore 1980). However, they complain about being frequently bored and lacking things to do (Vliet 1981) and report having fewer playmates in their suburban neighborhoods than in cities (Homel and Burns 1987). In suburbs, children and youth are dependent on others for transportation and want to have better public transportation systems that allow them to become more independent. 
Children and youth living in cities have identified the advantages of living close to shops, community centers, cinemas, and libraries (Vliet 1981). Close proximity to public transit has been found to be extremely valued because it increases children and youth mobility and allows them to visit multiple places for recreation (O’Brien 2003). On the other hand, children and youth living in the city complain about unfriendly people, noise, dirt, crime, and traffic (O'Brien 2003; Vliet 1981), and want a safe environment where they can be active (Urban Planning for Children Project 1986).

Children want places to socialize, where they can be with their friends and meet new people. Being in the public realm is very important to them; they want to be included in the neighborhood and to have a public space for themselves (O’Brien 2003). Young people want to be able to occupy public places that allow them personal freedom and lack authority figures (Owens 1988; Ertel 1975). In addition, parks and undeveloped areas where youth can be alone are desired characteristics of a community (Owens 1988; Ladd 1978).

Even though there are similarities among what children and youth have been found to value, it is important not to assume that all young people value the same things. For example, although several studies have found that teenagers value natural and undeveloped landscapes such as open fields, parks, and woods (Owens 1988; Hester et al. 1988; Lynch 1977; Moore 1980), others have found that many inner-city teens have had no prior experiences in natural places (Ladd 1978).

Perhaps the most comprehensive study identifying the factors that children and youth use to determine whether a place is desirable is the Growing Up in Cities Project conducted by UNESCO. This project was an international comparison study of several places, from large cities to rural areas, that took place in the 1970s and again in the 1990s. Many similarities were found in the ways that young people evaluated their communities across both time periods and all locations. The factors that led to high satisfaction ratings were categorized into six quality indicators: social integration, variety of interesting settings, safety and 
freedom of movement, peer meeting places, cohesive community identity, and green areas (Chawla 2002;

Driskell 2002), and their definitions are summarized below:

- Social integration - how welcome youth feel in their communities. Communities that possess social integration are ones in which young people are able to interact with other age groups in public places and have a sense of belonging and of being valued.

- Variety of interesting settings - a community in which young people have access to a range of places where they can meet with friends, play sports, join in community work, shop and run errands, be away from adult supervision, and observe action on the street.

- Safety and freedom of movement - a general sense of safety occurs when young people are familiar with the community, feel comfortable being there, and have the ability to move about freely and easily reach their destinations.

- Peer meeting places - niches in the community that youth can claim as their own places in which to socialize, such as plazas, empty lots, street corners, coffee shops, and community centers.

- Cohesive community identity - meaning that a place has clear geographic boundaries, that residents take pride in the history and culture of the place, and that a positive identity is expressed through festivals and art.

- Green Areas - these consist of some sort of vegetation that is accessible to young people, from flat grass playing fields to tree-shaded parks and wild, overgrown landscapes.

Although the Growing Up in Cities Project combines safety and freedom of movement into one single indicator, other studies indicate that although a place may be safe it may be extremely difficult to get around - such as an isolated suburb (Vliet 1981). On the other hand, a place may not be extremely safe 
for children and youth, such as the inner city, but it provides convenient access to public transit (O'Brien 2003). For the purpose of the present study, it was decided to consider safety and freedom of movement as two different quality indicators.

\section{Focus and Method of the Study}

The study was designed to determine whether adolescents — high school senior students—-throughout San Luis Obispo County perceive that their communities contain the quality indicators from the Growing Up in Cities Project, to uncover the degree of importance they place on these indicators, and to reveal any additional factors that determine whether a place is well liked by them. A combination of quantitative and qualitative methods was used to conduct a comparative analysis of the adolescents' evaluations of their communities. The three communities examined in this study are Cambria, Paso Robles, and San Luis Obispo, all of them are located in San Luis Obispo County, California. They were chosen because they vary in terms of their environments, demographic characteristics, and economic structures.

Cambria is a small town located in a beautiful spot on the coast along Highway 1 with about 6,500 residents - most of them retirees — with an economy based on tourism. Compared to the other two communities, the population of Cambria is older (median age is fifty-one), less diverse (91 percent of the population is white and 14 percent is Hispanic), and wealthier (median household income is $\$ 45,000$ ). Considered to be a rural coastal community, it is adamant about maintaining its village-like atmosphere. Because of community desires and environmental constraints, there has been little residential or commercial growth in Cambria during the last decade.

Paso Robles is a larger city along Highway 101 with a population of approximately 24,000 . The city has a younger (median age is thirty-three) and a more ethnically diverse population (76 percent white and 28 percent Hispanic), with a lower household income level $(\$ 39,000)$ and a greater number of families below the poverty level (11 percent) than the other communities. Paso Robes is primarily a residential 
community with a rapidly expanding economy based mainly on retail sales and the influx of big-box chains. Although the city has a nice downtown with a park wrapped by interesting historical architecture and retail, its newer areas look like any other American suburb. The town is surrounded by vineyards and other agricultural lands, making the wine industry an increasingly important economic factor.

The third community in the comparison is San Luis Obispo, site of the county government. With approximately 44,000 residents, its economy is based on education, tourism, recreation, accommodation, and food services. Its downtown has many historical buildings and a much-visited historic mission. In addition, the community holds a famous weekly farmers' market and other events. The city houses a large concentration of college students because of the Cal Poly San Luis Obispo campus, and the university has a major impact on the characteristics of the residents. The median age in San Luis Obispo is twenty-six, 84 percent of the population is white and 12 percent is Hispanic, the median household income is $\$ 32,000$, and 58 percent of the households are renter occupied. The community strongly supports the city's slow growth policies and the majority of new developments are commercial rather than residential. San Luis Obispo has a larger, more bustling downtown than either of the other two communities.

The study was conducted with senior students in government classes at one high school in each of the three study communities. Surveys were administered to obtain quantitative data and focus groups were used to obtain a richer, more in-depth understanding of their perceptions and values. In Cambria, one government class participated in this research with 20 students. At Paso Robles, five classes participated with a total of 119 students. At San Luis Obispo, two classes participated with a total of 59 students. The sample included both men (56 percent) and women (44 percent); most (98 percent) were either seventeen or eighteen years old, and the majority (59 percent) had lived in their communities for more than ten years. (No other demographic information was collected about the participants.)

The class periods during which the survey was administered ranged from seventy to ninety minutes and were divided into blocks of activities in the following order: 
1. Presentation about planning - after briefly introducing the purpose of the study, the first part of the class was devoted to a short presentation (fifteen minutes) about the nature of city planning. The issues addressed by the presentation included: the goals of city planning as being to protect the health, safety, and welfare of people; the value in separating land uses that conflict (such as industrial and residential) and some of the problems of overseparating them (environmental, transportation, and community identity); the new directions in planning as being smart growth, new urbanism, and mixed-use development; and planning as a political process that has impacts on youth and some of the ways for youth to participate in the planning process.

2. Evaluating a community's qualities - the students were then given a list of qualities that an ideal community should have based on the quality indicators identified by the Growing Up in Cities Project. They were asked to rate an ideal community on these qualities using a scale of importance.

3. Survey - students evaluated their own communities (Cambria, Paso Robles, and San Luis Obispo) using a survey designed to measure six quality indicators. The survey consisted of ten ratings, two open-ended questions, and several demographic questions.

4. Focus groups - the students were divided into groups of five or six with one research assistant that acted as a facilitator in each. Discussions were held around questions related to the positive and negative aspects of the participants' communities as well as additional qualities that they would use to evaluate a community.

5. Map anchored interviews - each student was given a simple map of their community and asked to identify certain features by placing stickers on their locations. Features included the town center, most and least favorite places, and favorite places to hang out with friends. After labeling their maps, the students discussed their answers. 


\section{Results of the Study}

\section{Survey Responses}

The first survey asked the students to read a list of seven statements describing characteristics that an ideal community should have, and then indicate how important they are on a four-point scale from not at all important to very important (table 1). Results showed that the top two qualities most rated as important or very important by students ( $>80$ percent) were "safety" and "plazas, community centers or courtyards to hang out in." "Being valued and respected by adults," "reliable transportation options," "parks and fields," and "variety of interesting settings" were rated as important by over 70 percent of the students. "Culture through art and festivals" was rated as important by less than 50 percent of the teens.

Comparisons among the communities showed few differences in the students' importance ratings. The only qualities in which there were significant differences included "reliable transportation options" $(F=$ $4.316, p<.05)$ and the presence of "plazas, community centers, or courtyards to hang out in" $(F=3.880$, $p<.05)$. Students in San Luis Obispo were less likely to rate "reliable transportation options" and "plazas, community centers, or courtyards to hang out in" as important than students in Cambria or Paso Robles.

The second survey was intended to determine whether the students felt that the characteristics identified in the first survey are present in their own community (Cambria, Paso Robles, or San Luis Obispo). It consisted of ten items on five-point rating scales and two open-ended questions. Table 2 indicates the percentage of students that agreed with the first nine rating questions and how they responded to the final rating question regarding whether they were satisfied with their community and its amenities. A majority of the students agreed that they "feel safe" in their community ( 66 percent) and "there are plenty of green areas which are accessible" (50 percent). About one-quarter of the students felt that their "opinions are valued and taken seriously by adults." The other characteristics received agreement ratings of less than 25 
percent. The results to the last question addressing general satisfaction showed that most of these teens were not satisfied with their communities, with only 18 percent rating that they were satisfied.

There were only two significant differences among the three study communities on these ratings. Students from Cambria were significantly less likely to believe their "community has a variety of interesting places" $(F=4.470, p<.05)$ and more likely to "feel safe" $(F=19.504, p<.05)$. All of the ratings of community characteristics significantly $(p<.01)$ correlated with the overall satisfaction rating. The most powerful correlations with community satisfaction were with "community has a variety of interesting places," "there are plazas where people can get together to socialize," and teens" "opinions are valued and taken seriously by adults" $(r=.50, .47$, and .40 , respectively).

The two open-ended questions asked students the following: "what is your favorite thing about your community and why?" and "if you could do anything to change your community, what would it be and why?" Students could provide multiple answers to each question, and a content analysis was conducted on the data. The most common three answers for each community are presented in tables 3 and 4 .

Results show that students valued the small town feeling in their community, and the related characteristics of friendly people, people know each other, and safety. In more urban San Luis Obispo, adolescents also valued access to surrounding natural areas and the developed downtown area. Even though the San Luis Obispo adolescents socialize in the downtown and the Paso Robles adolescents socialize in their community park, students in all three communities wanted more places to hang out and socialize with other adolescents, which could be in stores, malls or recreation areas. The adolescents in San Luis Obispo felt displaced by the large number of college students living in the town, while adolescents in Cambria and Paso Robles wanted more alternative places for socializing with other adolescents. Although community parks are available for socializing in all three communities, police discourage adolescents from gathering in parks, especially at night. 
Demographic questions (age, gender, and number of years lived in the community) were included in the survey to characterize the respondents. Statistical tests showed that these background variables did not significantly relate to the students' responses.

\section{Focus Groups}

Using a modified version of the interview guide developed for the Growing Up in Cities Project, students were divided into groups of five or six and asked questions regarding their perception of the positive and negative features of their community, and the changes occurring in the communities. Interviews lasted approximately twenty-five minutes.

When asked what they like most about their community, the students in all three communities discussed the small town atmosphere, beautiful location, safety, and access to natural areas. They enjoy the fact that they are able to run into people they know almost everywhere they go. They feel comfortable almost everywhere in their community. The urban places they listed as feeling the most comfortable included their own home, friends' houses, recreational facilities (movies, gym, etc.), and urban parks. They also enjoy the open space, agricultural lands, mountains, and proximity to beaches.

When asked what they like to do, the students responded that they go to coffee shops, restaurants, movies, or beaches; socialize with their friends; hang out at one of the parks in town; or go hiking. They enjoy playing basketball, skateboarding, surfing, and other sports. Those who participate in community service activities have fun and feel like they make a positive contribution to the community. The students in San Luis Obispo had more positive views of their community because of the larger downtown and greater availability of places, events, and activities for them.

Even though the students in all of the communities complained that there is not much to do there, they said that they like their town and believe it is a good place to grow up, especially for young children. They observed that teenagers in every city are dissatisfied with their community and that every place gets boring no matter how big or small it is. Having a car makes the community more bearable to them, 
especially the smaller communities. Once teenagers have a license and a vehicle, they can really benefit from the best of both worlds. They have the freedom to enjoy small town living and then drive to a larger city for entertainment.

Boredom was the students' biggest complaint about their community, especially in Cambria and Paso Robles. They venture out of town regularly to visit other communities to find something to do. When asked whether they would be more likely to hang out in town if there were more amenities for people their age, they acknowledged the constraints involved in improving the community for youth. In Cambria, many said that if a movie theater or shops that catered to adolescents were located in the community, they would not survive because the youth population is not large enough to support them.

The youth complained that they are prevented from some recreational activities and places because they are not allowed or it is too expensive for them. In Cambria, the students complained that recreational facilities were oriented toward wealthy retirees, while the students in Paso Robles and San Luis Obispo discussed how the police prevented them from gathering in public places to recreate. Community centers have limited hours and cater to young children and the elderly. When they hang out in parks, the police tell them to move even when they are not causing any trouble. They have been asked to stop hanging out in front of stores because they allegedly scare customers away, and are kicked out of stores even when they are legitimate customers. They are harassed by security guards in downtown shopping plazas, and are threatened by the bouncers at bars even when they are not trying to enter these establishments. Students experience being looked at with suspicion by adults when they are just hanging out.

Adolescents feel that their lives are overregulated. In Paso Robles, the high school is a closed campus, so students are not allowed to leave for lunch. This makes them feel like prisoners. Paso Robles and San Luis Obispo have city curfew laws that prevent them from being on the streets after certain hours. Students perceive the police to have a bad attitude and believe they crack down too hard on small things 
because they have nothing better to do. The police are more concerned about intimidating people than protecting the community.

Skateboarding is another source of contention, since many adolescents want to skateboard around town on streets and sidewalks. Skateboarding is regulated in all of these communities, and teenagers skating down the sidewalks are stopped by the police. Students view skateboarding as a form of transportation and are annoyed when they are stopped. They were excited when new skate parks were first built, but now skaters find them boring and one rarely sees teenagers actually using the parks.

The Paso Robles and San Luis Obispo students do not like how spread out their communities are becoming, which makes them more dependent on cars. In Cambria, the small size and isolation of the community forces adolescents to drive to other cities for entertainment. They believe that driving is bad for the environment; however, the transit system is not very convenient. The local bus system has few bus stops, the stops are not located near residential areas, and the bus service runs infrequently. Before the students had cars, they walked, rode their bikes or skateboards, and got rides from friends or parents. The students without access to vehicles said that they usually stay at home and have no life. This was less of a problem for the San Luis Obispo adolescents because they have a better transit system that links residential areas to the downtown.

These adolescents expressed fear and concerns about certain elements in their communities. In Paso Robles, low-income housing developments were referred to as "ghettos" and perceived as places where more crime occurs, crazy people reside, and drugs are used. In San Luis Obispo, students expressed fear of homeless people, who they believe often have mental problems. Although they feel bad for the homeless, they are uncomfortable going near places where the homeless hang out and do not like taking buses because the homeless ride them.

The students in Paso Robles and San Luis Obispo perceive that their communities are growing rapidly and that this growth is generally not for the better. They complained about how the influx of new people 
is causing increased traffic congestion and overcrowding in their schools. They were frustrated that most of the new residential development is expensive single-family homes when there is a real need for more affordable housing. In Paso Robles, most of the commercial development is "big box" commercial centers, which they feel are adding to the traffic and creating competition with the smaller downtown businesses.

Many students in Paso Robles and San Luis Obispo are sensitive to environmental issues and expressed anger and sadness that the remaining agricultural fields and open space around their communities are being developed. Growth is destroying the pristine natural environment that once existed there. The students used to play in these fields and natural areas - places they are no longer allowed to go or that no longer exist.

Urban growth was also blamed for compromising the safety they once had in their community, especially in Paso Robles. It used to be safe to walk around at night but now some of the female students are afraid to go anywhere by themselves. Female students often experienced being honked or whistled at, something they said was new in their community.

The students in Paso Robles and San Luis Obispo did mention a few benefits from the new development. They liked having more stores for shopping and realized that commercial development is helping to boost the city's economy. However, they would rather have malls or more shops in the downtown than large, Wal-Mart-type stores. They do not like the sprawling development pattern that is occurring because it is makes traffic worse and public transit options are not available.

When asked what they would like to see in future, students in all three communities wanted more active things for youth to do. The adolescents wanted more recreational facilities and places where they can just hang out without having to buy something. Even if they just want to sit somewhere, such as at a coffee shop, they have to purchase a beverage. The expense of everything limits their ability to find things to do. Several mentioned that a mall would be a nice addition since it would provide them with a place they 
could walk around or sit and watch people without necessarily having to buy something. Interestingly, at the same time that the students were talking about the types of developments that would improve their lives, they feared that any more development would harm the small town character that makes their community a desirable place to live.

\section{Map Anchored Interviews}

For the map anchored interviews, students were given a map of their community and asked to label the town center, the paths they take, their least favorite places, their favorite places to hand out with friends, and their favorite places to go by themselves.

For the town center, the students in San Luis Obispo labeled the downtown commercial area, while the students in Cambria and Paso Robles chose specific places like parks, restaurants, or stores. Students in all three communities labeled schools as their least favorite places. The Cambria and Paso Robles students also marked apartment buildings and low income housing areas while the San Luis Obispo students mentioned the university. All of the students marked their homes as one of their favorite places. In addition, students in Cambria marked the beach and, in Paso Robles, Wal-Mart, while in San Luis Obispo they marked the downtown. The most popular place to hang out was at friends' homes for all of the communities. Cambria students also labeled a popular restaurant, Paso Robles students selected the downtown park, and San Luis Obispo students again selected their downtown.

The students liked places where they have more freedom to express their individuality, such as their own homes and friend's houses, places that draw a crowd of people together, places where they can be with friends in public, and places where they can be outside and alone such as hiking trails and natural vistas. They disliked places where they are highly controlled such as school and work. The results of the mapanchored interviews were similar in each community, reinforced the findings of the survey and discussion groups, and revealed the types of places that youth value and that planners should strive to incorporate into their communities. 


\section{Discussion and Ideas to Increase the Qualities that Adolescents Value}

The adolescents in this study believed that safety and places to hang out and socialize were the most important quality indicators. Most of the other quality indicators (social integration, variety of interesting settings, freedom of movement, and green areas) were also rated as important by the majority of these adolescents. The only quality indicator not rated as important for them was expressing community identity through cultural activities such art and festivals. This indicator may not have been rated important because many of the existing public events in these communities are dedicated to adults or young children; adolescents are often overlooked or excluded from community events. In general, the students taking part in this study in these three communities agreed on the importance of the quality indicators, with the exception of those from San Luis Obispo, who were less likely to rate transportation and places to hang out and socialize as important in an ideal community. Probably because its larger downtown provides easy access to places where students can socialize, they are less aware of the importance of this feature in their city.

Respondents rated their communities fairly low on the quality indicators, and only safety and access to green areas were given a positive rating by the majority of them. The negative ratings on these indicators correlated with their overall dissatisfaction with their communities. The quality factors with strongest correlations to overall satisfaction were having a variety of interesting places, places where students can socialize, and their opinions valued by adults. The open-ended questions of the survey showed that although the students liked the safety, small town feel, and natural areas of their communities, they were bored by the lack of recreational areas and places to meet and socialize.

The focus group discussions reinforced survey findings. Again, the positive aspects of the communities were small town feel, safety, and access to natural areas. The negative aspects were boring places without much to do, limited places to hang out and socialize, transportation problems and dependence on cars, and overcontrol by adults, including harassment when hanging out, limits on skateboarding, curfews, and 
school regulations. Generally, the students viewed the changes and growth occurring in their communities negatively. Growth is perceived as destroying the natural areas they value, increasing traffic and school crowding problems, and reducing safety. They recognized that although they want more places to shop, recreate, and socialize, they are getting more suburban developments and "big box" stores that do not meet their needs and increase transportation problems. These results are similar to the existing research on urban and rural adolescents (O’Brien 2003; Vliet 1981; Homel and Burns 1987). Compared to urban youth, rural youth like the sense of community, safety, and access to green areas provided by their communities, but complain of isolation, boredom, limited activities, control by adults, and transportation problems.

In the presentation that was given to introduce students to the concept of city planning, a brief segment was dedicated to showing them the new directions represented by new urbanism, mixed-use, and transitoriented development. Students expressed how much they liked these ideas during the group discussions. They talked about how much new suburban development with tract homes that look almost identical is taking away from the unique character of their communities. In addition, these new homes are being built further and further away from the downtown area. Those that end up living there and do not have a car find it extremely difficult to get around and visit their friends. The students believed that compact, new urbanist, and transit-oriented design can help to strengthen social integration and increase freedom of movement.

The results of this research have both substantive and process implication for planners. The concerns and complaints of these adolescents may be addressed by planning and design solutions. Because the biggest complaint among the adolescents in each of the study communities is boredom, an attempt should be made to support interesting settings and mixed-use areas, and to create an identifiable town center that is easily accessible by alternative means of transportation. The town center should be highly visible and designed with proper seating to allow the adolescents (as well as other residents in the community) to watch the action but also to serve as a peer meeting place. 
This center should host regular activities and events to draw people, such as music concerts, cultural festivals, and farmer's markets. It is not enough for events to only occur a few times a year; they should be held frequently and the activities they promote need to vary. Although many towns promote festivals and other activities that technically contribute to the cohesive community identity indicator, they are generally geared toward adults or children and do not necessarily benefit adolescents. Giving adolescents the opportunity to participate in community events could help them complete important developmental tasks, such as establishing satisfying social relationships and learning how to use free time wisely.

Accessibility is another important area in planning and design that should consider the needs of youth. More effective public transportation options and the implementation of alternative modes of transportation should be considered, including skateboarding. A system of paths for skateboarding away from the public eye and incorporating jumps and other such elements could help adolescents recreate and move more freely in the community. Along the same lines, widening recreational opportunities for adolescents is also fundamental, such as adapting existing community centers and providing free sport activities not formally related to school.

From a process perspective, cities and counties should make an effort to reach out and get adolescents effectively involved in the planning and designing of their communities, and this participation should be at a meaningful level and initiate shared decisions with adults. Schools and planning staff have to educate youth on how the planning system works, on how they can contribute, and on instruments such as the General Plan. Youth should be given opportunities to participate in the making and updating of plans, and perhaps in the making of a "youth element" in general and specific plans. Youth councils with members elected by their peers and with an effective role in county and city governance would be an effective step toward empowering youth and letting them take more active roles in their communities.

There are important benefits to increasing participation of adolescents in the planning process. The existing research literature shows that adolescents have the cognitive and social capabilities for 
meaningful participation. Participation programs not only provide important information to planners, but also help promote the psychosocial development of adolescents. The results of our research shows that adolescents (high school seniors) do not feel valued by the adults in their communities, that they enjoy participating in community service activities, and that they are sensitive to the social and environmental problems caused by growth in their communities. These students are prepared to meaningfully participate and have important views to express.

\section{Final Remarks}

The first research question that this study sought to answer was "are the quality indicators identified by previous research important to adolescents in San Luis Obispo County?” The findings suggest that the quality indicators are important to adolescents; however, the degree of importance placed on each indicator varies from community to community. Our second research question was "are these indicators present in communities within San Luis Obispo County and do they influence how adolescents evaluate their communities?" The results indicate that adolescents—-high school seniors_-perceive safety and green areas in their communities, but believe that their communities lack social integration, cohesive community identity, freedom of movement, peer meeting places, and a variety of interesting settings. These results are similar to other research on the attitudes of urban and rural adolescents about their communities.

The adolescents in this study recognized that cities are not responsive to the issues they find important. Policies have been adopted that are intended to restrict the activities and movement of youth, such as curfew laws and anti-skateboarding ordinances. In addition, the sprawling pattern of growth that these communities are experiencing is hindering the movement of youth. Those that live in the homes that are being built further away from downtown centers have difficulty getting to places to meet up with their friends. Oftentimes, they complain that they "have no life." Even those that have personal vehicles that allow them the freedom to travel to other places complain of boredom. Their communities lack a variety 
of interesting settings and places where they can hang out with their friends. These problems show the need to increase efforts to reach out to youth and involve them in the process of planning their communities. Young people often do not have a choice about where they grow up, but they should have the option to do what it takes to improve the situation in which they live.

From both a substantive and process perspective, cities are not being designed with the concerns and needs of adolescents in mind. One of the main causes of these problems is the negative attitudes and fears adults have about teens. Some adults do not want to share their public spaces with teens and do not value the opinions of teens. Like other forms of prejudice, the solution is increased contact or interaction between the groups. By including teens into the planning process and developing public spaces that are valuable to both teens and adults, adults can learn that their prejudices about teens are unfounded. By participating and interacting with adults, teens can learn how to become citizens who care about their communities.

Findings also suggest that although parents may perceive a suburban community to be the ideal setting to raise their children, adolescents do not necessarily feel the same way. Suburban communities may be safe and contain an abundance of parks and green areas for young children to enjoy; however, adolescents tend to complain of boredom and feel frustrated with their lack of freedom to get to places where they can socialize with friends and meet new people. The adolescents in this study were briefly exposed to concepts of smart growth such as transit-oriented development and mixed-use, and the design concepts of new urbanism that are meant to facilitate neighbor interaction. These ideas intrigued them and they expressed their desire to see these concepts integrated into their communities.

Two major conclusions may be taken from this study. First, not only should public policies and zoning codes consider the needs, values, and opinions of youth, but youth need to participate in decision-making processes. Providing for the youth will generate a healthier city and contribute to the formation of better and more engaged future citizens. Second, adolescents value smart-growth concepts, such as compact and 
mixed-use development, and modes of alternative transportation. This should be a call to parents who still believe that suburban neighborhoods are ideal places to raise their children, as well as to hesitant developers and investors who insist in traditional sprawl as the only adequate response to the housing market. Smart growth concepts may help create healthier and safer communities where adolescents may find plenty to do, meet their peers and socialize, and have increased mobility. The importance of integrating youth into city life should not be underestimated. 


\section{References}

Adelson, J. 1991. Political development. In Encyclopedia of adolescence,edited by R. Lerner, A. Peterson, and J. Brooks-Gunn. New York: Garland Publishers.

Bechtel, R. 1997. Environment and behavior: An introduction. Thousand Oaks, CA: Sage.

Chawla, L. 2002. Growing up in an urbanizing world. London: Earthscan.

Checkoway, B., and L. Gutierrez. 2006. Youth participation and community change: An introduction. Journal of Community Practice 14 (1): 1-9.

Cole, M., S. Cole, and C. Lightfoot. 2005. The development of children, 5th ed. New York: Worth Publishers.

Donnelly, D. 1980. The child in the environment. Built Environment 6 (1): 62-67.

Driskell, D. 2002. Creating better cities with children and youth: A manual for participation. London: Earthscan.

Duffet, A., J. Johnson, and S. Farkas. 1999. Kids these days '99. What Americans really think about the next generation. New York: Public Agenda.

Erikson, E. 1964. Childhood and society. New York: Norton.

Ertel, M. 1975. Programming and evaluating teenage "hanging places." Childhood City Newsletter 1 (3): 2 .

Frank, K. 2006. The potential of youth participation in planning Journal of Planning Literature 20 (4): 351-71. 
Glendinning, A., M. Nuttall, L. Hendry, M. Kloep, and S. Wood. 2003. Rural communities and wellbeing: A good place to grow up? Sociological Review 15 (1): 129-56.

Hester, R. T., Jr., M. J. McNally, S. Hale, and M. Lancaster. 1988. We'd like to tell you . ..: Children's views of life in Westport, California. Small Town 18 (4): 19-24.

Homel, R., and A. Burns. 1987. Is this a good place to grow up in? Neighborhood quality and children's evaluations. Landscape and Urban Planning 14:101-16.

Kerr, J., L. Frank, J. Sallis, and J. Chapman. 2007. Urban form correlates of pedestrian travel in youth: Differences by gender, race, ethnicity and household attributes. Transportation Research: Transportation and Environment 12 (May): 177-82.

Ladd, F. C. 1978. City kids in the absence of . . In Humanscape: Environments for people, edited by R. Kaplan and S. Kaplan. North Scituate, MA: Duxbury Press.

Lynch, K. 1977. Growing up in cities: Studies of the spatial environment of adolescence in Cracow, Melbourne, Mexico City, Salta, Toluca, and Warszawa. Cambridge, MA: MIT Press.

McMeeking, D., and B. Purkayastha. 1995. “I can’t have my mom running me everywhere”: Adolescents, leisure, and accessibility. Journal of Leisure Research 27 (4): 360-78.

Medoff, P., H. Sklar. 1994. Streets of hope. Boston: South End Press.

Miller, J., and J. Piscatelli. 2004. State citizenship education policies. http://www.ecs.org (Accessed December 20, 2004).

Moore, R. C. 1980. Collaborating with young people to assess their landscape values. Ekistics 281:128-135.

- 1986. Childhood's domain: Play and place in child development. London: Croom-Helm. 
Mullahey, R., Y. Susskind, and B. Checkoway. 1999. Youth participation in community planning. Chicago: American Planning Association.

O'Brien, M. 2003. Regenerating children's neighborhoods: What do children want? In Children in the city: Home, neighborhood, and community, edited by P. Christensen and M. O'Brien. London: Routledge/Falmer.

Owens, P. (1988). Natural landscapes, gathering places, and prospect refugees: Characteristics of outdoor places valued by teens. Children's Environments Quarterly 5 (2): 17-24.

- 2002. No teens allowed: The exclusion of adolescents from public spaces. Landscape Journal 21 (1): 156-63.

Piaget, J. 1967. The child's conception of the world. Totowa, NJ: Littlefield.

Rapoport, A. 1977. Human aspects of urban form: Toward a man-environment approach to urban form and design. Oxford, UK: Pergamon Press.

- 1982. The meaning of the built environment: A non-verbal communication approach. Beverly Hills, CA: Sage.

Rutter, M. 1979. Fifteen thousand hours: Secondary schools and their effects on children. Cambridge, MA: Harvard University Press.

Sanoff, H. 1994. School design. New York: Van Nostrand Reinhold.

-2000. Community participation methods in design and planning. New York: John Wiley and Sons.

-2002. Schools designed with community participation. Washington, DC: National Clearing House for Educational Facilities. 
Sewell, W., and J. Coppock (eds.). 1977. Public participation in planning. London: John Wiley and Sons.

Simpson, B. 1997. Towards the participation of children and young people in urban planning and design. Urban Studies 34 (5/6): 907-25.

Stokols, D. and S. Shumaker. 1981. People in places: A transactional view of settings. In Cognition, social behavior, and the environment, edited by J. Harvey. Hillsdale, NJ: Lawrence Earlbaum.

Stoneman, D. 1988. Leadership development: A handbook from the youth action program of East Harlem block schools. New York: Youth Action Program.

Tuan, Y. F. 1974. Topophilia: A study of environmental perception, attitudes and values. Englewood Cliffs, NJ: Prentice Hall.

1977. Space and place: The perspective of experience. Minneapolis, MN: The University of Minnesota Press.

Urban Planning for Children Project. 1986. Planning Sacramento: Views of students and parents. Sacramento, CA: Urban Interdependencies.

Vliet, W. 1981. Neighborhood evaluations by city and suburban children. American Planning Association Journal 47:458-66.

Whitman, D. 2005. The next great generation? Fears about today's teens aren't new—or always right. US News and World Report Special Edition: Mysteries of the Teen Years, April. 


\section{Tables}

Table 1: Characteristics of an ideal community (rated as important and very important, in percentages).

\begin{tabular}{|c|c|c|c|c|}
\hline & Cambria & Paso Robles & San Luis Obispo & Total \\
\hline Teenagers are valued and respected by adults & 90 & 76 & 72 & 76 \\
\hline $\begin{array}{l}\text { There are reliable transportation options for } \\
\text { young people }\end{array}$ & 85 & 78 & 56 & 72 \\
\hline There are several parks and fields to play in & 55 & 74 & 70 & 71 \\
\hline It is a safe community & 90 & 95 & 96 & 94 \\
\hline $\begin{array}{l}\text { There are plazas, community centers, or } \\
\text { courtyards for teens to hang out in }\end{array}$ & 75 & 81 & 71 & 80 \\
\hline $\begin{array}{l}\text { The community has expressed its culture } \\
\text { through art and festivals }\end{array}$ & 30 & 48 & 34 & 42 \\
\hline $\begin{array}{l}\text { The community has a variety of interesting } \\
\text { settings }\end{array}$ & 75 & 74 & 62 & 70 \\
\hline
\end{tabular}


Table 2: Rating the qualities of the community (percentage agree and strongly agree).

Cambria Paso Robles San Luis Obispo Total

I have a sense of belonging and of being valued in my community

19

My community has a variety of interesting places where people my age can get together, shop or run

5

15

14

errands, talk, play games, and be away from adults

I feel safe in my community

100

55

78

66

I take pride in the history and culture of my community

24

15

I participate in or attend the festivals and cultural activities that occur within my community

My opinions are valued and taken seriously by the adult residents in my community

There are plazas, street corners, courtyards, coffee shops, and/or community centers in my community

where people my age can get together and socialize

It is easy for teens to find reliable, safe, and convenient transportation to get to the places they want to go

There are plenty of green areas in my community that are accessible to me, such as tree shaded parks, flat grass playing fields, forests, or pastures

Overall, how satisfied are you with your community and its amenities for people your age? 
Table 3: Favorite aspects of the community.

Cambria

Small town feel $\quad 42$

$\begin{array}{ll}\text { People are friendly } & 37\end{array}$

$\begin{array}{ll}\text { Safe } & 21\end{array}$

Paso Robles

$\begin{array}{ll}\text { Small town feel } & 23\end{array}$

Everyone knows each other $\quad 15$

$\begin{array}{ll}\text { Parks } & 14\end{array}$

San Luis Obispo

Surrounding natural environment $\quad 32$

$\begin{array}{ll}\text { Safe } & 27\end{array}$

Downtown 20 
Table 4: Desired improvements in the community (in percentages).

Cambria

Develop more places to hang out $\quad 58$

$\begin{array}{ll}\text { Build recreational facilities } & 37\end{array}$

$\begin{array}{lr}\text { Build more stores/malls } & 21\end{array}$

Paso Robles

Develop more places to hang out 39

Build recreational facilities $\quad 20$

$\begin{array}{ll}\text { Build more stores/malls } & 15\end{array}$

San Luis Obispo

Develop more places to hang out $\quad 31$

$\begin{array}{ll}\text { Build more stores/malls } & 17\end{array}$

$\begin{array}{ll}\text { Fewer college students } & 17\end{array}$ 